\title{
Composition and Morphology Investigation of NiCoB Nanoparticles, as-Prepared and Coated by $\mathrm{SiO}_{2}$
}

\author{
Ivana Lončarek, Anđelka M. Tonejc, Željko Skoko, ${ }^{*}$ Nikolina Novosel, \\ Mislav Mustapić, and Krešo Zadro
}

Department of Physics, Faculty of Science, University of Zagreb, Bijenička cesta 32, HR-10000 Zagreb, Croatia

RECEIVED FEBRUARY 6, 2013; REVISED SEPTEMBER 23, 2013; ACCEPTED OCTOBER 14, 2013

\begin{abstract}
NiCoB nanoparticles, as-prepared and coated by $\mathrm{SiO}_{2}$, were synthesized by chemical reduction of metallic salts. The as-prepared samples were additionally annealed at $650^{\circ}$ for 1 hour in argon atmosphere. All samples (the as-prepared and annealed ones) were investigated by X-ray powder diffraction (XRD), field emission scanning electron microscopy (FE-SEM) and energy dispersive spectroscopy (EDS). According to FE-SEM observations each of the investigated samples was composed of nearly spherical nanoparticles with average dimension smaller than $30 \mathrm{~nm}$. Also, tendency of formation of irregular agglomerates was present in both cases of the as-prepared and annealed investigated samples. XRD measurements of as-prepared samples revealed fully amorphous structure. In case of annealed samples, crystallization of different phases was confirmed (as a consequence of heat treatment at $650{ }^{\circ} \mathrm{C}$ ). The existence of these phases was also observed from FE-SEM micrographs as different morphologies present in the samples.(doi: 10.5562/cca2234)
\end{abstract}

Keywords: amorphous $\mathrm{NiCoB}$ nanoparticles, X-ray diffraction, Rietveld refinement, scanning electron microscopy (SEM), energy dispersive X-ray analysis (EDS)

\section{INTRODUCTION}

Magnetic nanoparticles have attracted much interest recently due to their novel properties and versatile applications (e.g. in biomedicine, ${ }^{1-3}$ microelectromechanical / nanoelectromechanical (MEMS/NEMS) devices, ${ }^{4}$ giant magnetoresistance (GMR) sensors $^{5}$ etc.). The point essential for the study of fine particles is the production of samples of narrow and reproducible size distribution. A well known method for preparation of alloys in the form of fine particles (particularly ternary transition metal-boron alloys) is the chemical reduction of aqueous solution of metallic salts, with alkali metal borohydride as the reducing agent. ${ }^{6-8}$ It has been shown that the amount of boron strongly affects the magnetic behaviour of such alloys (as it alters the band structure and Fermi density of states). ${ }^{9}$ Alloys chemically reduced by alkali metal borohydride have nanosized morphology and consequently higher surface area and activity than those prepared by some physical methods (for example, rapid melt quenching method by which alloys are produced in form of thin ribbons ${ }^{10-12}$ ) and can be amorphous $^{13-15}$ or amorphous/crystalline. ${ }^{16,17}$ By systematically adjusting various parameters - time, temperature, concentration and chemistry of starting materials, sur- factants and solvents - it is possible to control the morphology (i.e. size and shape) and therefore the properties of nanoparticles.

The aim of this investigation was to obtain nanosized particles with well defined dimensions (10 $30 \mathrm{~nm}$ ) and relatively narrow size distribution using chemical reduction synthesis. Silica shell was used in order to stabilize the nanoparticles (e.g. to reduce oxidation of the core, to control the distance between the particles thus reducing their magnetic interaction, previously reported on example of $\mathrm{Co}-\mathrm{Ni}$ based nanoparticles $\left.^{18}\right)$. The resulting microstructures were examined by X-ray powder diffraction (XRD), field emission scanning electron microscopy (FE-SEM) and energy dispersive spectroscopy (EDS).

\section{EXPERIMENTAL PROCEDURE}

\subsection{Synthesis of NiCoB nanoparticles}

$\mathrm{NiCoB}$ nanoparticles were synthesised by the chemical reduction of metallic salts. Metallic salts, $\mathrm{Ni}\left(\mathrm{NO}_{3}\right)_{2}$ and $\mathrm{CoCl}_{2}$, were dissolved in ethanol and reducing agent $\mathrm{KBH}_{4}$ was dissolved in water. The fractions of metallic salts and reducing agent were adjusted to yield the com-

\footnotetext{
* Author to whom correspondence should be addressed. (E-mail: zskoko@phy.hr)
} 
position $\mathrm{NiCoB}$ as the product of the synthesis. The synthesis was performed in a closed system with argon atmosphere and all solutions were bubbled with argon for two hours prior to the reaction. The reaction temperature was $273 \mathrm{~K}$. A black powder was formed instantly and it was extracted from the solution by vacuum filtration. It was subsequently washed with distilled water to remove residual ions and then rinsed with acetone to remove water. The powder was dried for three hours in argon atmosphere. In order to prepare $\mathrm{NiCoB}$ particles coated by $\mathrm{SiO}_{2}, 50 \mathrm{ml}$ of ethanol containing $0.1 \mathrm{ml}$ tetraethoxysilan (TEOS) was added immediately after the addition of $\mathrm{KBH}_{4}$. An amount of the resulted powder was annealed at $650^{\circ} \mathrm{C}$ for $1 \mathrm{~h}$ in the flowing argon atmosphere.

The expected chemical reaction forming the uncoated $\mathrm{NiCoB}$ nanoparticles is:

$$
\begin{aligned}
& \mathrm{Ni}\left(\mathrm{NO}_{3}\right)_{2}(\mathrm{aq})+\mathrm{CoCl}_{2}(\mathrm{aq})+4 \mathrm{KBH}_{4}(\mathrm{aq}) \rightarrow \\
& \rightarrow \mathrm{NiCoB}(\mathrm{s})+\mathrm{KNO}_{3}(\mathrm{aq})+\mathrm{KCl}(\mathrm{aq})+\mathrm{H}_{2} \mathrm{O}(1)
\end{aligned}
$$

In the case of coating of $\mathrm{NiCoB}$ nanoparticles with $\mathrm{SiO}_{2}$, TEOS was firstly transformed into the - $\left(\mathrm{SiO}_{2}\right)-$ polymers in weak acidic environment (ethanol) according to the equation:

$$
\begin{aligned}
\mathrm{Si}\left(\mathrm{OC}_{2} \mathrm{H}_{5}\right)_{4}(\mathrm{l})+ & \mathrm{H}_{2} \mathrm{O}(\mathrm{l})+\mathrm{H}^{+}(\mathrm{aq}) \rightarrow \\
& \rightarrow-\left(\mathrm{SiO}_{2}\right)-+4 \mathrm{C}_{2} \mathrm{H}_{5} \mathrm{OH}(1)
\end{aligned}
$$

and then added to solution with already formed $\mathrm{NiCoB}$ nanoparticles. Through linking of these polymers coating around $\mathrm{NiCoB}$ nanoparticles was formed, with thickness depending on amount of TEOS and $\mathrm{pH}$ of the solution.

\subsection{XRD and FE-SEM}

Powder samples were characterized by XRD at room temperature using a Philips PW 1820 counter diffractometer with monochromatized $\mathrm{Cu} K \alpha$ radiation (graphite monochromator) in Bragg-Brentano geometry. XRD patterns were recorded in the $2 \theta$ range from 10 to $70^{\circ}$, scanned in steps of $0.02^{\circ}(2 \theta)$. The counting time was 1 second per step for as-prepared samples with uncoated particles and for as-prepared samples with particles coated by $\mathrm{SiO}_{2}$, and 4 seconds per step for annealed samples and annealed samples with particles coated by $\mathrm{SiO}_{2}$.

Morphology (i.e. size and shape) and elemental composition of samples were investigated by FE-SEM and EDS, using JEOL FE-SEM 7000F microscope (resolution: $1.2 \mathrm{~nm}$ at $15 \mathrm{kV} ; 3 \mathrm{~nm}$ at $1 \mathrm{kV}$ ) equipped with an X-ray detector for EDS. For FE-SEM investigations, the as-prepared and annealed samples were put on a carbon tape, while the samples with coated particles were put on a silver paste. Both substrates were used in order to avoid electrical charge accumulation on the sample surface. The silver paste was used in order to avoid a difficulty regarding the detection of boron as its characteristic radiation is close to that of carbon. Element mapping of specific regions of a sample was also performed in order to determine the spatial distribution of the element of interest. Measuring time was set to 20 min per element.

\section{RESULTS AND DISCUSSION}

\subsection{XRD and FE-SEM}

According to XRD patterns, Figure 1, the as-prepared NiCoB samples, with uncoated particles and particles coated with $\mathrm{SiO}_{2}$ coating, were fully amorphous, indicated by a broad amorphous maximum located at around $2 \Theta \approx 45^{\circ}$, where the diffraction lines of $\mathrm{NiB}$ and also $\mathrm{Ni}_{2} \mathrm{~B}\left(\mathrm{Co}_{2} \mathrm{~B}\right)$ are situated.

XRD patterns indicated that the annealed sample contained four phases $-\mathrm{NiO}$ and/or $\mathrm{CoO}, \mathrm{Ni}, \mathrm{Ni}_{3}\left(\mathrm{BO}_{3}\right)_{2}$ and/or $\mathrm{Co}_{3}\left(\mathrm{BO}_{3}\right)_{2}$ and $\mathrm{B}_{2} \mathrm{O}_{3}$, whereas annealed sample with coated particles contained two phases $-\mathrm{NiO}$ and/or $\mathrm{CoO}$, and $\mathrm{Ni}_{3}\left(\mathrm{BO}_{3}\right)_{2}$ and/or $\mathrm{Co}_{3}\left(\mathrm{BO}_{3}\right)_{2}$. $\mathrm{NiO}$ and $\mathrm{CoO}$ are isostructural, and so are $\mathrm{Ni}_{3}\left(\mathrm{BO}_{3}\right)_{2}$ and $\mathrm{Co}_{3}\left(\mathrm{BO}_{3}\right)_{2}$; therefore these phases cannot be distinguished by XRD with certainty. The XRD patterns of the two samples are shown in the Figure 2.

Mass fractions of the corresponding phases present in the two annealed samples, obtained by the Rietveld refinement, as well as the calculated sizes of the coherent diffraction domains, are given in Tables 1

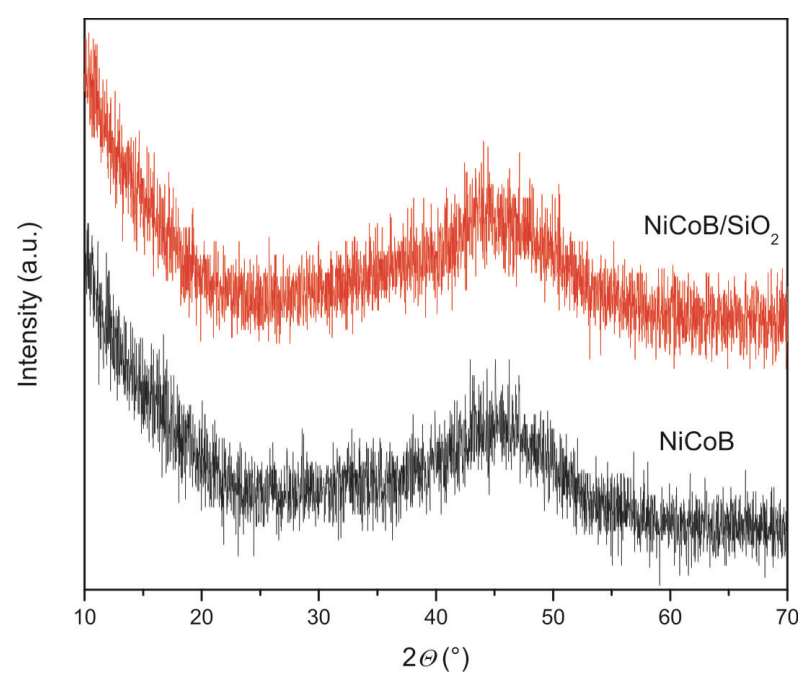

Figure 1. XRD patterns of as-prepared samples. The pattern of the sample with coated particles is shown in the upper part of the Figure. 


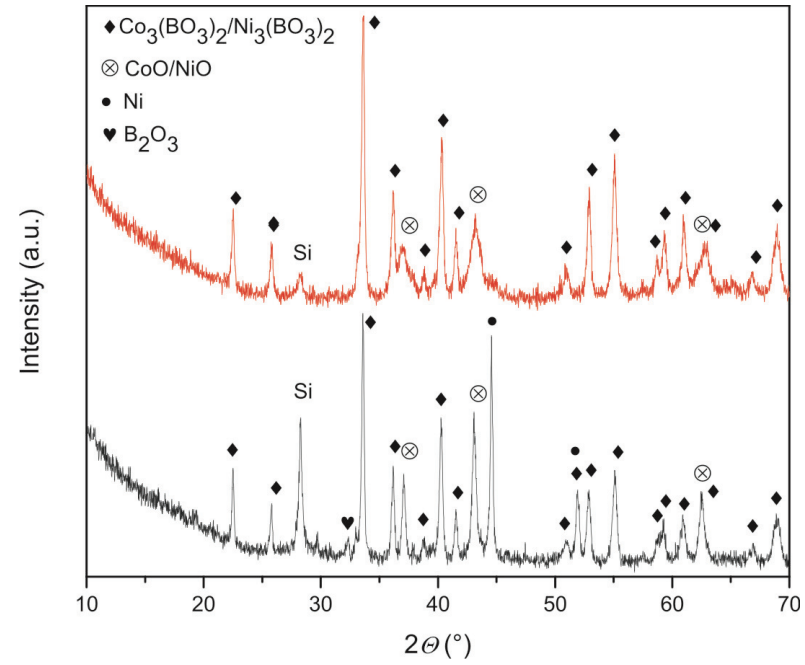

Figure 2. XRD patterns of annealed samples. The pattern of the sample with coated particles is shown in the upper part of the Figure. Diffraction line at $2 \Theta \approx 28^{\circ}$ is from the silicon sample holder.

and 2. The absence of $\mathrm{NiB}$ and $\mathrm{Ni}_{2} \mathrm{~B}\left(\mathrm{CO}_{2} \mathrm{~B}\right)$ in case of the annealed samples (seen as lack of diffraction lines around $2 \Theta \approx 45^{\circ}$ in Figure 2) indicates an oxidation of the samples during high temperature annealing. One of the possible reactions through which this can take place is: $2 \mathrm{NiB}+3 \mathrm{O} \rightarrow 2 \mathrm{Ni}+\mathrm{B}_{2} \mathrm{O}_{3}$ (which would also explain presence of $\mathrm{Ni}$ and $\mathrm{B}_{2} \mathrm{O}_{3}$ confirmed by Rietveld analysis in case of annealed NiCoB sample with uncoated particles, Table 1). The same type of the reaction is also proposed in literature on the example of chemically reduced $\mathrm{Fe}_{2} \mathrm{~B}$ nanoparticles. ${ }^{19,20}$

It should be noted that the presence of oxides in case of all investigated as-prepared and annealed samples cannot be avoided completely despite their synthesis under special conditions (Ar atmosphere in our case $)^{21}$. One of the possible explanations of this oxidation phenomenon given in literature (regarding the oxidation of magnetic nanoparticles synthesized in argon flow) is that small amount of oxygen pollution is present in the media of inert gas ${ }^{22}$. Also, water used in preparation procedure of the samples could also be the source of oxygen which was not completely removed by argon bubbling.

Table 1. Rietveld analysis of annealed NiCoB sample with uncoated particles ( $w p$ and $R w p$ expressed in \%)

\begin{tabular}{llc}
\hline \multicolumn{2}{l}{ Uncoated particles } & $\boldsymbol{w p}=\mathbf{6 . 1 6}, \boldsymbol{R} \boldsymbol{w p}=\mathbf{7 . 9 5}$ \\
\hline Phase & mass fraction $/ \%$ & size $/ \mathrm{nm}$ \\
\hline $\mathbf{C o O}$ & $20.1(3)$ & 25 \\
$\mathbf{N i}$ & $12.0(2)$ & 48 \\
$\mathbf{N i}_{\mathbf{3}}\left(\mathbf{B O}_{\mathbf{3}}\right)_{\mathbf{2}}$ & $57.9(6)$ & 59 \\
$\mathbf{B}_{\mathbf{2}} \mathbf{O}_{\mathbf{3}}$ & $10.0(8)$ & 54 \\
\hline
\end{tabular}

Table 2. Rietveld analysis of annealed NiCoB sample with coated particles ( $w p$ and $R w p$ expressed in \%)

\begin{tabular}{|c|c|c|}
\hline \multicolumn{2}{|c|}{$\mathrm{SiO}_{2}$-coated particles } & $w p=5.94, R w p=7.70$ \\
\hline Phase & mass fraction $/ \%$ & size / nm \\
\hline $\mathrm{CoO}$ & $25.6(5)$ & 8 \\
\hline $\mathrm{Ni}_{3}\left(\mathrm{BO}_{3}\right)_{2}$ & $74.4(8)$ & 33 \\
\hline
\end{tabular}

Crystal structures of the phases present in the annealed samples were refined by the Rietveld method. Starting structural models were taken from the Inorganic Crystal Structure Database (2011) as follows: No. 245320 for $\mathrm{CoO}$ (Zen et al. 2006), 5265 for Ni (Jette and Foote 1935), 2016 for $\mathrm{Ni}_{3}\left(\mathrm{BO}_{3}\right)_{2}$ (Pardo et al 1971), and 24047 for $\mathrm{B}_{2} \mathrm{O}_{3}$ (Berger, 1953). Rietveld refinement was performed by the program X'Pert HighScore Plus, version 2.1 (PANalytical 2004), using a pseudo-Voigt profile function and polynomial background model. Profile function parameters (FWHM, asymmetry, peak shape) and structrural parameters for each phase were refined with the exception of atomic coordinates on special positions. Thermal displacement parameters were assumed and refined as isotropic. The preferredorientation correction did not significantly improve the fit.

FE-SEM micrographs of as-prepared sample with uncoated particles (Figure 3) and as-prepared sample with coated particles (Figure 4), and the micrographs of annealed sample (Figures 5 and 6) and annealed sample with coated particles (Figure 7) reveal that each sample is composed of nearly spherical nanoparticles. One can also notice that there is a tendency of formation of irregular agglomerates present in both cases of the asprepared and annealed samples. This can easily be explained by magnetic nature of the nanoparticles as men-

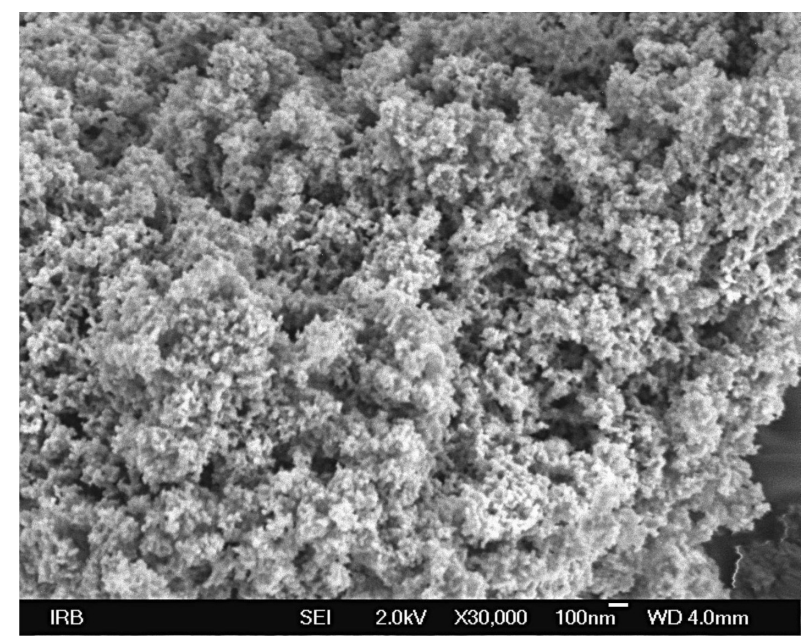

Figure 3. FE-SEM micrograph of as-prepared sample with uncoated particles. 


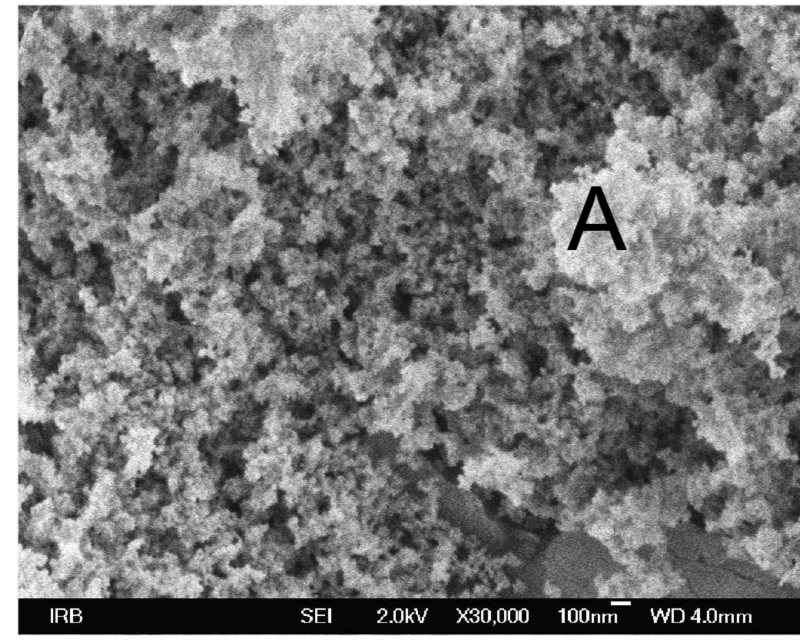

Figure 4. FE-SEM micrograph of as-prepared sample with coated particles. Region marked with A is a residual from the sample preparation.

tioned earlier ${ }^{18}$. The presence of these agglomerates in case of as-prepared samples with coated particles may not necessarily exclude the formation of $\mathrm{SiO}_{2}$ coating. In fact, as can be seen from elemental mapping observations there is an indication that thin $\mathrm{SiO}_{2}$ coating is formed.

A large smooth structure, present in the as-prepared sample with coated particles (e.g. region marked with A in Figure 4), is a residual from the sample preparation (according to EDS analysis of the region, not shown in this paper). In case of the annealed sample with uncoated particles large plate-like structures (e.g. the one marked

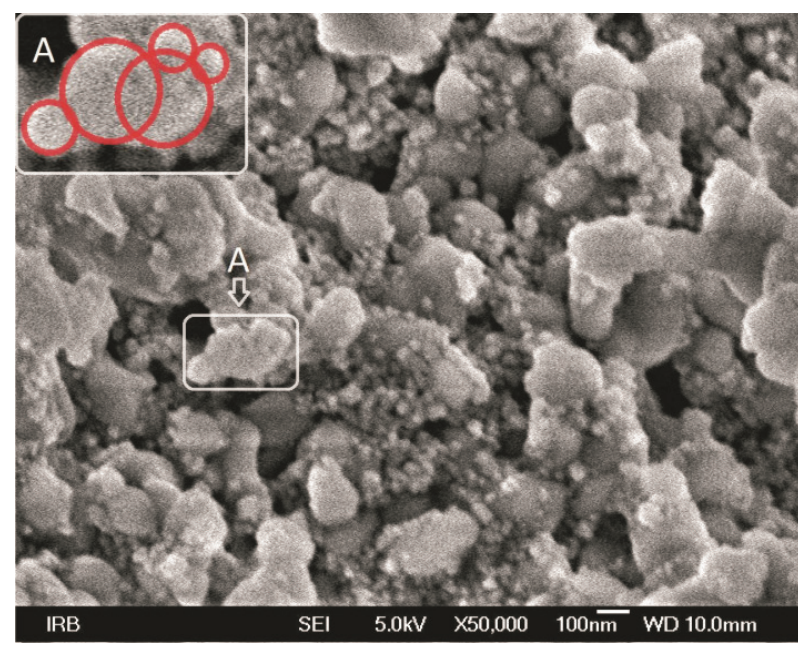

Figure 5. FE-SEM micrograph of the annealed sample with uncoated particles representing one of three observed different morphologies present in the sample in the form of plate-like structures (marked with $\mathrm{A}$ in the Figure). Inset inside the Figure shows magnified plate-like structure A which is composed of nearly spherical forms clustered together.

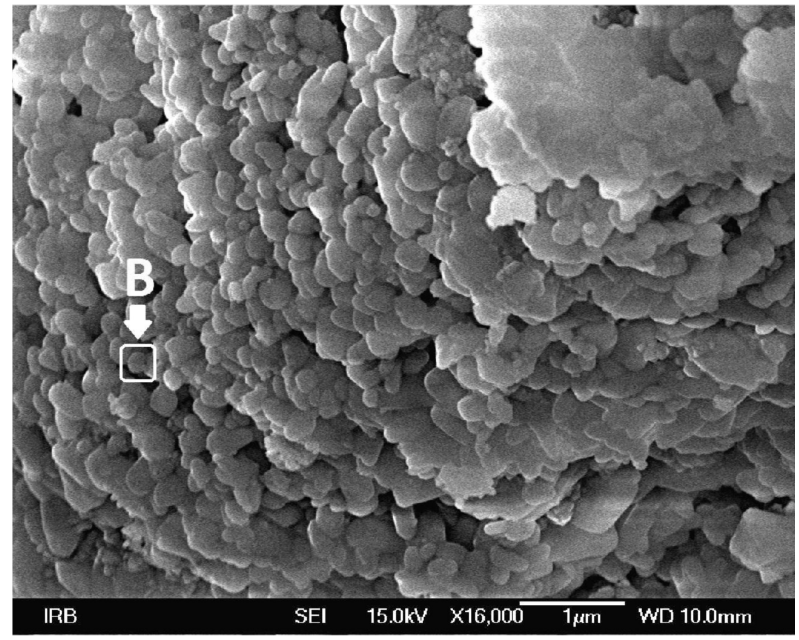

Figure 6. FE-SEM micrograph of annealed sample with uncoated particles representing one of three different morphologies present in the sample in the form of smooth spheres (marked with B).

with A in Figure 5) are observed (along with irregular agglomerates of nanoparticles as in the case of the asprepared samples) which are probably the results of oxidation. These structures can also be observed for the annealed sample with coated particles (e.g. A in Figure 7). A closer inspection of Figure 5 reveals that these structures are in fact composed of large nearly spherical forms that are clustered together (inset in the Figure). One more morphology in form of smooth spheres (B) is also present in case of the annealed sample with uncoated particles (Figure 6). These different morphologies observed in case of the annealed samples (with coated and uncoated particles) could indicate the formation of different phases in the investigated samples (as confirmed by $\mathrm{XRD)}$ as a consequence of heat treatment.

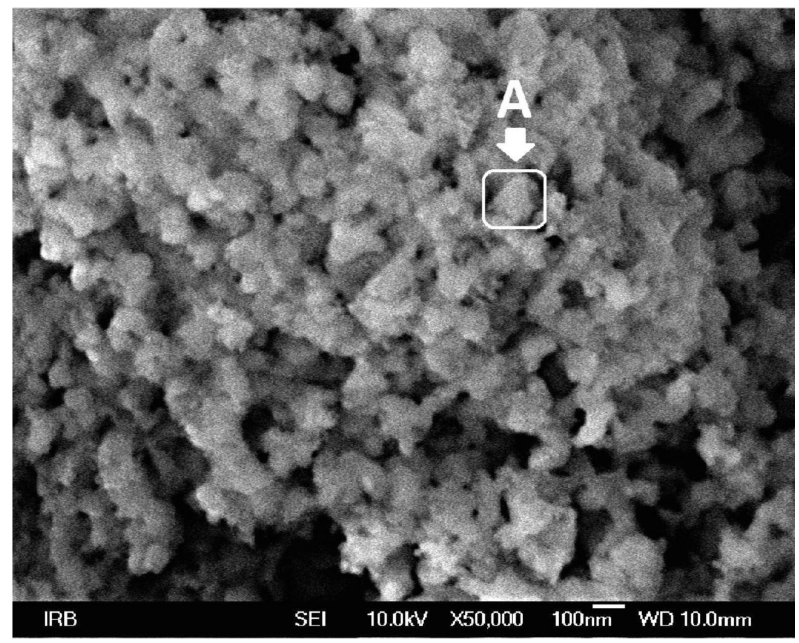

Figure 7. FE-SEM micrograph of annealed sample with coated nanoparticles which shows typical morphology present in the sample in form of plate-like structures (marked with A). 


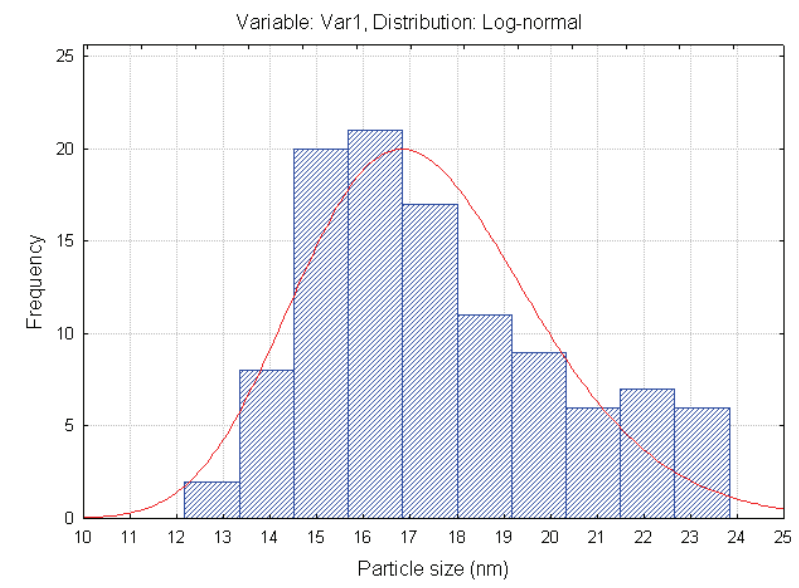

Figure 8. Spherical particle size distribution for as-prepared sample with uncoated particles.

Statistical analysis was performed by the commercial software Statistica. It was found that the particle size distribution (from corresponding FE-SEM micrographs) could be fitted best against lognormal distribution (for both as-prepared and annealed samples), as can be seen in Figures 8 and 9 on the example of spherical particle size distributions for the as-prepared $\mathrm{NiCoB}$ sample and as-prepared $\mathrm{NiCoB}$ sample with coated nanoparticles, respectively. Histograms of sizes of corresponding morphologies observed in case of the annealed samples follow the same type of distribution and are not shown in this paper. The lognormal size distribution of nanoparticles prepared by chemical reduction synthesis is also reported in literature, in case of $\mathrm{CoNiB}$ and $\mathrm{FeCoB}$ nanoparticles. ${ }^{14,15}$ It should also be noted that the observed lognormal size distribution for the annealed samples (which consist of fully crystalline phases) is in good agreement with previously published

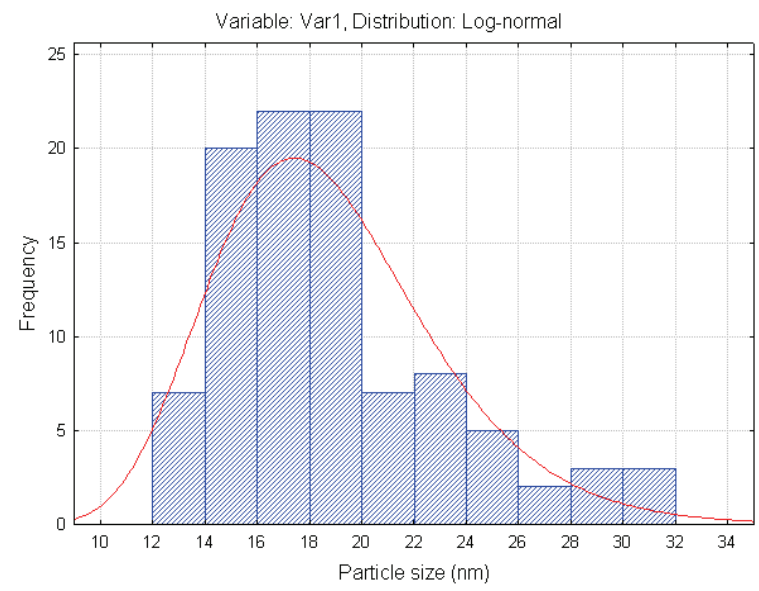

Figure 9. Spherical particle size distribution for as-prepared sample with coated nanoparticles.

results on particle size distribution in nanocrystalline samples. $^{23,24}$

The average sizes of typical structures observed in the as-prepared and annealed samples with coated and uncoated particles are listed in Table 3 . It can be seen that coated as-prepared particles display slightly larger average diameters than the uncoated ones. This could be due to formation of thin $\mathrm{SiO}_{2}$ coating as the result of adding of small concentration of TEOS at the beginning of the synthesis reaction ${ }^{25}$. Also, the average size of the spherical particles present in the annealed uncoated particles is larger than that of asprepared ones indicating the microstructure change as a consequence of heat treatment at $650^{\circ} \mathrm{C}$. In the case of annealed coated particles the average particle sizes are smaller than uncoated ones. It can be supposed that the $\mathrm{SiO}_{2}$ coating inhibits the growth of crystal grains.

Table 3. Parameters of the different structures observed in the as-prepared and annealed samples with uncoated and coated particles by FE-SEM

\begin{tabular}{|c|c|c|c|}
\hline Sample & $\begin{array}{l}\text { Typical structures present } \\
\text { in the sample }\end{array}$ & $\begin{array}{l}\text { Number of analyzed } \\
\text { structures }\end{array}$ & Structure's diameter / nm \\
\hline $\begin{array}{l}\text { As-prepared } \\
\text { with uncoated particles }\end{array}$ & spherical particles & 107 & $17 \pm 3$ \\
\hline $\begin{array}{l}\text { As-prepared with } \\
\text { coated particles }\end{array}$ & spherical particles & 99 & $19 \pm 4$ \\
\hline \multirow{3}{*}{$\begin{array}{l}\text { Annealed with } \\
\text { uncoated particles }\end{array}$} & spherical particles & 116 & $25.8 \pm 0.5$ \\
\hline & $\begin{array}{l}\text { nearly spherical structures which form } \\
\text { plate like agglomerates }\end{array}$ & 92 & $73 \pm 8$ \\
\hline & smooth spherical agglomerates & 102 & $150 \pm 11$ \\
\hline \multirow{2}{*}{$\begin{array}{l}\text { Annealed with } \\
\text { coated particles }\end{array}$} & spherical particles & 80 & $17 \pm 1$ \\
\hline & $\begin{array}{l}\text { nearly spherical structures which form } \\
\text { plate like agglomerates }\end{array}$ & 80 & $46 \pm 3$ \\
\hline
\end{tabular}



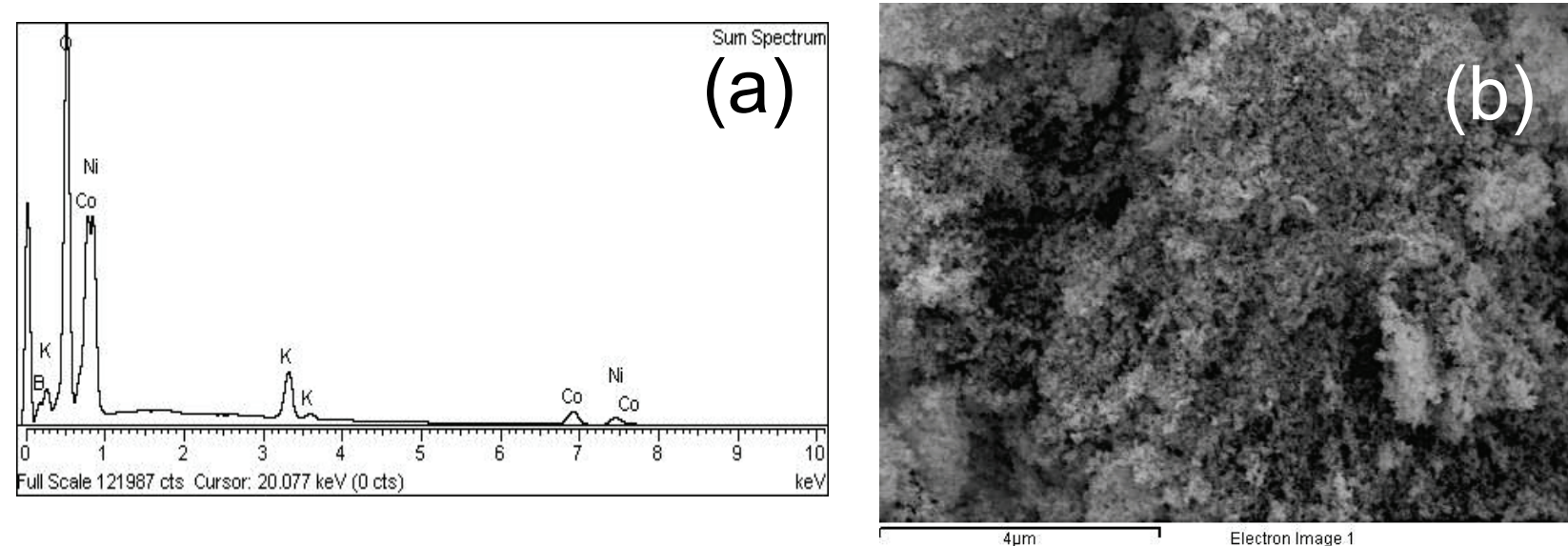

Figure 10. EDS sum spectrum of as-prepared sample with uncoated particles (a) taken from a whole region of the sample shown in (b). Note: sum spectrum is an average spectrum of sum of local spectra taken at each point of the region of the sample shown in the Figure (b).

\subsection{EDS Analysis in Specific Region of Sample and Mapping}

EDS sum spectrum of as-prepared NiCoB sample with uncoated particles and the region of the sample from which the spectrum is taken are shown in Figures 10 (a) and (b), respectively. According to this spectrum, as well as to corresponding spectrum of the sample with coated particles, Figure 11 (a), taken from the region of the sample shown in Figure 11 (b), both samples are composed of $\mathrm{Ni}, \mathrm{Co}, \mathrm{B}, \mathrm{O}$ and $\mathrm{K}$, with exception of few at. \% of $\mathrm{Si}$ (due to addition of TEOS) and Ag (since a conductive silver paste was used as a substrate in order to avoid electrical charging of the sample) observed in the case of the sample with coated particles. It should be noted that sum spectrum shown in Figure 10 (a) represents an average spectrum of sum of local spectra taken at each point of the region of the sample presented in Figure 10 (b).

Quantitative EDS analysis (where $\mathrm{B}, \mathrm{CaCO}_{3}$, $\mathrm{SiO}_{2}, \mathrm{~K}-\mathrm{MAD}-10$ Feldspar, $\mathrm{Co}$ and Ni were used as standards) of various regions of the investigated samples reveals that average $\mathrm{Ni}$ :Co ratio remains unchanged $(\approx 1.1)$, Table 4 , despite of the observed local deficiency of $\mathrm{Ni}$ and $\mathrm{Co}$ and surplus of $\mathrm{O}$ (up to 50 at.\%) in some regions (probably due to undesired reaction products which were not completely washed out). The presence of $\mathrm{K}(\approx 1$ at. $\%)$ in both $\mathrm{NiCoB}$ samples with uncoated and coated particles, can be explained as a left-over from the sample preparation (since $\mathrm{KBH}_{4}$ was used as the reducing agent) ${ }^{26}$, while the detected surplus of $\mathrm{O}$ is the result of oxidation of the sample.

EDS spectra of annealed sample with uncoated particles (Figures 12 (a) and 13 (a) taken at specific regions of the sample (Figures 12 (b) and 13 (b)) reveal that this sample is also composed of the same elements as in case of the as-prepared samples, with exception of few at. \% of $\mathrm{C}$ detected in some of the investigated regions (due to application of conductive carbon tape as a substrate). According to EDS analysis results, two
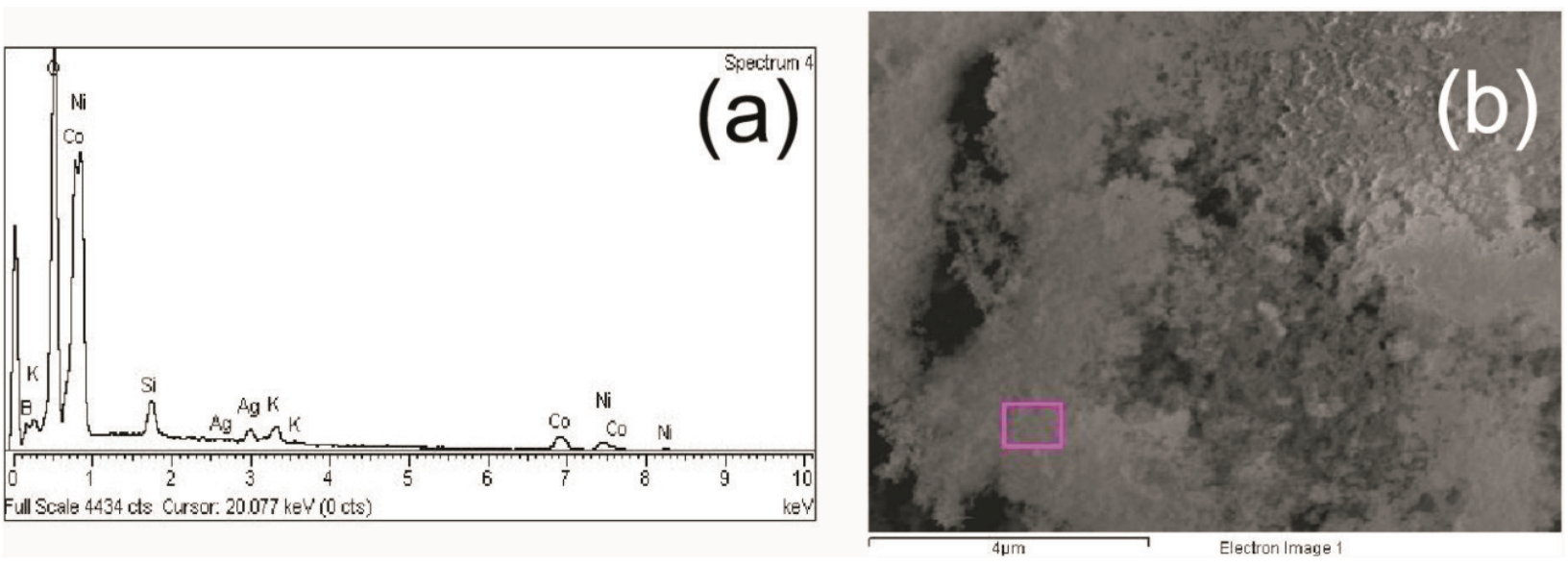

Figure 11. EDS spectrum of as-prepared sample with coated particles (a) taken at a specific region of the sample shown in (b). The observed Ag in the Figure (a) is a response from silver paste substrate. 
Table 4. EDS quantitative analysis of as-prepared and annealed samples with uncoated and coated particles

\begin{tabular}{lcc}
\hline Sample & $\begin{array}{c}\text { Number of different regions of the sample at } \\
\text { which EDS analysis was performed }\end{array}$ & Average Ni:Co ratio \\
\hline as-prepared uncoated particles & 7 & $1.1 \pm 0.1$ \\
as-prepared coated particles & 4 & $1.1 \pm 0.1$ \\
annealed uncoated particles & 4 & $1.07 \pm 0.04$ \\
annealed coated particles & 4 & $1.2 \pm 0.1$ \\
\hline
\end{tabular}

different morphologies present in the sample in form of irregular plate-like agglomerates and smooth spherical agglomerates earlier observed from FE-SEM micrographs (marked as A in Figure 5 and $\mathrm{B}$ in Figure 6, respectively) most probably consist of $\mathrm{Co}_{3}\left(\mathrm{BO}_{3}\right)_{2}$ or $\mathrm{Ni}_{3}\left(\mathrm{BO}_{3}\right)_{2}$ in first case and $\mathrm{Ni}, \mathrm{Co}$ in the second case, which is supported with XRD observations. According to XRD observations of the sample (obtained by the Rietveld refinement), the phases $\mathrm{Co}_{3}\left(\mathrm{BO}_{3}\right)_{2}$ and/or $\mathrm{Ni}_{3}\left(\mathrm{BO}_{3}\right)_{2}$ are the major phases in the sample, Table 1 . The presence of these type of borates is also confirmed in literature in case of chemically reduced CoNiB nanoparticles ${ }^{15}$. These observations along with that yielding from FE-SEM investigations of various regions of the samples (which showed that the plate-like morphology is the most common morphology present in the investigated sample) indicate that the main response in EDS spectrum in Figure 12 (a), taken at region with plate-like morphology (Figure 12 (b)), is that from the major phase present in the samples (therefore most part of the detected oxygen and boron in case of corresponding quantitative elemental analysis, Table 5, is from the
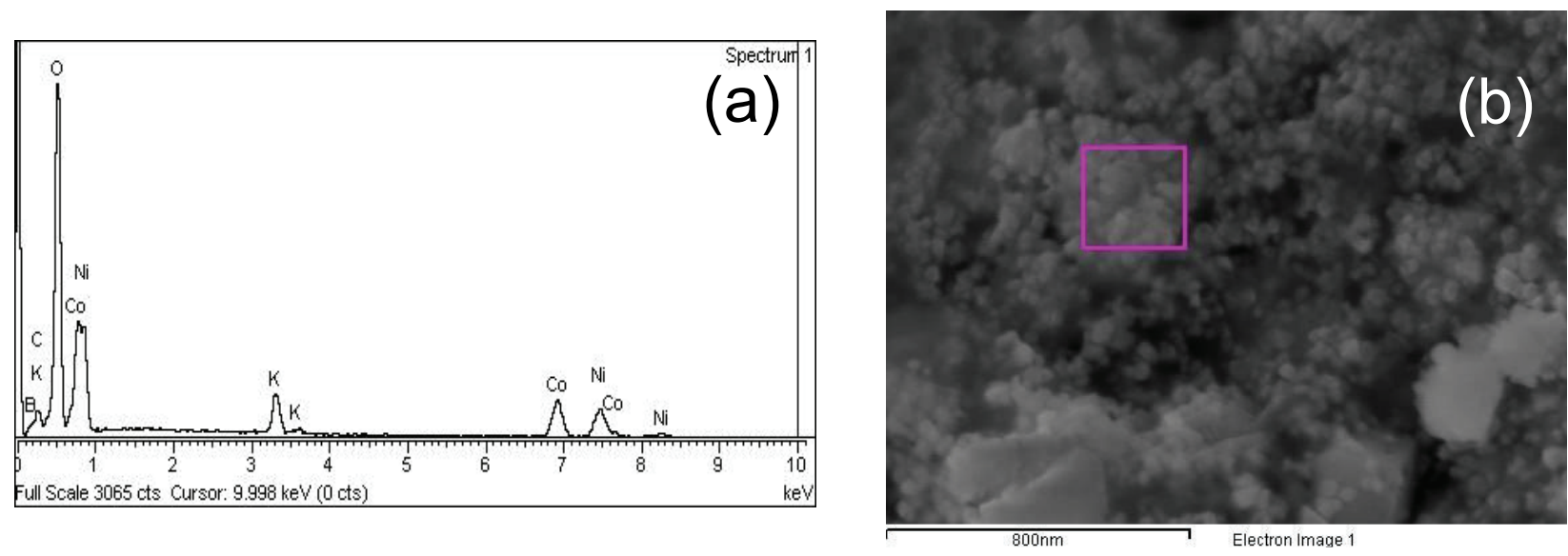

Figure 12. EDS spectrum (a) of annealed sample with uncoated particles taken at region with plate-like morphology (b), placed bellow spherical particles.
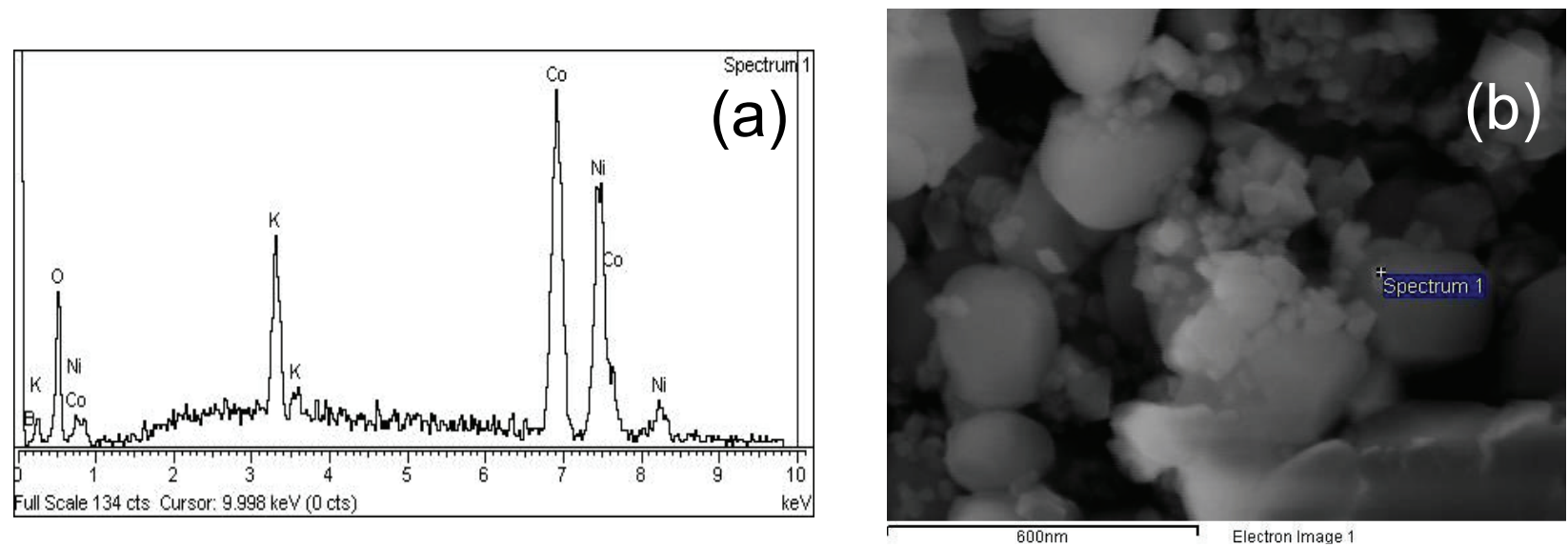

Figure 13. EDS spectrum (a) of annealed sample with uncoated particles taken at region with smooth spheres (b). 
Table 5. Quantitative elemental analysis of the region shown in Figure 12 (b) with corresponding EDS shown in Figure 12 (a)

\begin{tabular}{ccc}
\hline Element & Mass fraction $/ \%$ & Atomic fraction $/ \%$ \\
\hline B $K$ & 12.79 & 24.51 \\
C $K$ & 5.13 & 8.84 \\
O $K$ & 39.26 & 50.84 \\
K $K$ & 4.04 & 2.14 \\
Co $K$ & 19.76 & 6.95 \\
Ni $K$ & 19.03 & 6.72 \\
Total & 100.00 & 100.00 \\
\hline
\end{tabular}

mentioned borates). The measured dimension of this phase obtained from XRD observations is in good agreement with that from earlier FE-SEM observations for nearly spherical structures which form plate like agglomerates as can be seen from Tables 1 and 3 (as well as from Tables 2 and 3 for the sample with coated particles).

The chemical composition of the third morphology present in the sample, in form of spherical particles (second of the most common morphology), was difficult to be determined since in all of the investigated cases it was located extremely close to larger irregular agglomerates or even bellow them (as in Figure 12 (b)), so the main response in EDS analysis was that from $\mathrm{Co}_{3}\left(\mathrm{BO}_{3}\right)_{2}$ and/or $\mathrm{Ni}_{3}\left(\mathrm{BO}_{3}\right)_{2}$. EDS analysis of regions of the sample containing smooth spherical agglomerates (Figure 13 (b)) having average size of about $150 \mathrm{~nm}$, earlier evidenced in Figure 6, reveals much larger fractions of $\mathrm{Ni}$ and Co (up to 30 at. \%, given in Table 6) while detected fraction of $\mathrm{B}$ and $\mathrm{O}$ are much smaller (nearly two times for $\mathrm{B}$ and four times for $\mathrm{O}$ ). In all of previously investigated regions of different morphologies, detected fractions of $\mathrm{Ni}$ and $\mathrm{Co}$ were about 7 at. \% (as in Table 5). These larger fractions of $\mathrm{Ni}$ and $\mathrm{Co}$ (along with much smaller fraction of $\mathrm{B}$ and $\mathrm{O}$ ) observed at the regions with these specific morphologies indicate that smooth spherical agglomerates are mostly composed of $\mathrm{Ni}$ and Co as reported in literature ${ }^{18}$, in which presence of pure $\mathrm{Ni}, \mathrm{Co}$ and $\mathrm{Co}-\mathrm{Ni}$ alloy nanoparticles was confirmed. However, there is no evidence for formation of such alloys in our case. Moreover, XRD observations didn't confirm the formation of $\mathrm{Co}$-Ni phase.

The statement that smooth spherical agglomerates are mainly composed of $\mathrm{Ni}$ and $\mathrm{Co}$ is supported with XRD observations regarding the absence of $\mathrm{Ni}$ (and $\mathrm{Co}$ ) in case of the annealed sample with coated nanoparticles (upper part of Figure 2) for which such morphology wasn't observed in any case of FE-SEM investigation of various regions of the sample (typical example of such regions without mentioned morphologies is represented in Figure 7).
Table 6. Quantitative elemental analysis of the region shown in Figure 13 (b) with corresponding EDS shown in Figure 13 (a)

\begin{tabular}{ccc}
\hline Element & Mass fraction $/ \%$ & Atomic fraction $/ \%$ \\
\hline B $K$ & 3.27 & 13.86 \\
O $K$ & 4.34 & 12.42 \\
K $K$ & 4.56 & 5.34 \\
Co $K$ & 45.02 & 34.99 \\
Ni $K$ & 42.81 & 33.39 \\
Total & 100.00 & 100.00 \\
\hline
\end{tabular}

Presence of $\mathrm{Ni}$ in case of annealed sample with uncoated nanoparticles can be explained by partial oxidation of intermediate phase $\mathrm{NiB}\left(\mathrm{Ni}_{2} \mathrm{~B}\right)$ due to annealing of the as-prepared uncoated sample (according to earlier proposed chemical reaction).

EDS quantitative analysis of the annealed sample with coated particles indicates that in this case most probably only $\mathrm{Co}_{3}\left(\mathrm{BO}_{3}\right)_{2}$ or $\left.\mathrm{Ni}_{3}\left(\mathrm{BO}_{3}\right)_{2}\right)$ and $\mathrm{NiO}$ or $\mathrm{CoO}$ are formed (as was proved by XRD observations, Table 2, which is in good agreement with FE-SEM and EDS observations regarding absence of smooth sphere morphologies composed mostly of $\mathrm{Ni}$ and $\mathrm{Co}$ ). The chemical reactions during annealing of the sample obviously took place trough different path in respect to earlier proposed one for its uncoated counterpart since neither $\mathrm{Ni}$ nor $\mathrm{B}_{2} \mathrm{O}_{3}$ phases was observed in that case. Furthermore, this sample, unlike annealed sample with uncoated particles, also contains a few at. \% of $\mathrm{Si}$, which, along with detected $\mathrm{O}$, could indicate that $\mathrm{SiO}_{2}$ coating has been formed. This conclusion is in a good agreement with the result in Table 3 that spherical nanoparticles for the annealed sample with coated particles have smaller sizes in respect to the uncoated particles in the annealed sample (since the formation of the coating probably inhibits the crystallite growth during the heat treatment). The lack of $\mathrm{SiO}_{2}$ phase in the corresponding XRD pattern is due to very small amount of this phase present in the sample (in accordance with earlier EDS observations regarding very low fraction of observed $\mathrm{Si}-$ few at. \%) which is close related to small concentration of TEOS added at the begging of the synthesis reaction.

It is important to mention the fact that the average $\mathrm{Ni}: \mathrm{Co}$ ratio in the investigated annealed samples also remains unchanged $(\approx 1.1)$ despite of the observed local deviations of $\mathrm{Ni}$ and $\mathrm{Co}$ fractions depending on the region at which EDS analysis was performed (as shown for the case of the sample with uncoated particles). When compared with the Ni:Co ratio in the as-prepared sample, one can observe that it remains unchanged (despite of the heat treatment), Table 4.

To reveal the spatial distribution of constituent elements in examined samples the elemental mapping 


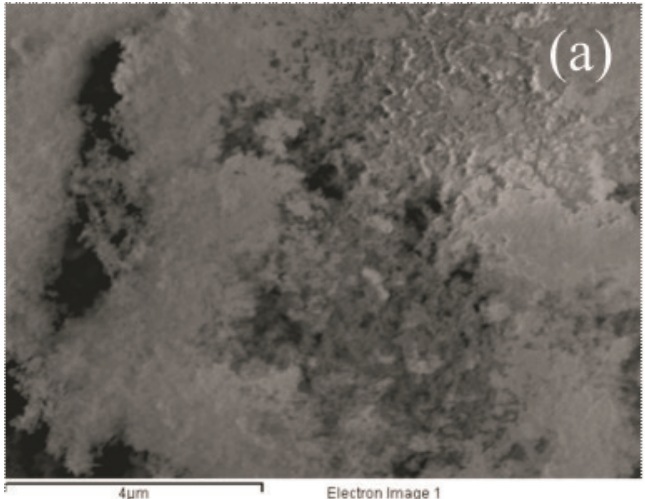

Electron Imag̣e 1

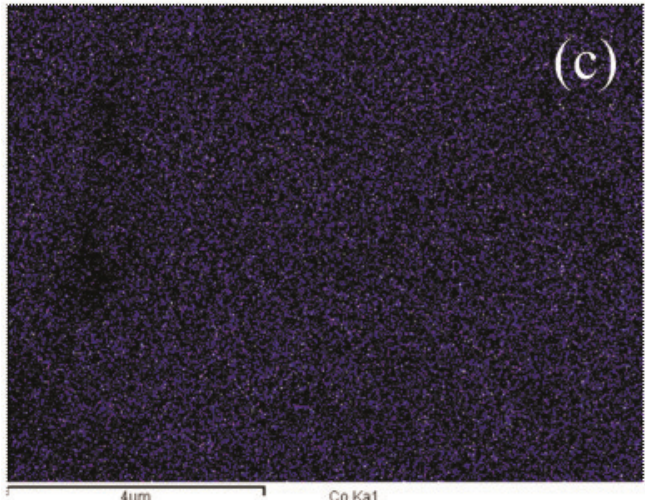

Co Ka1
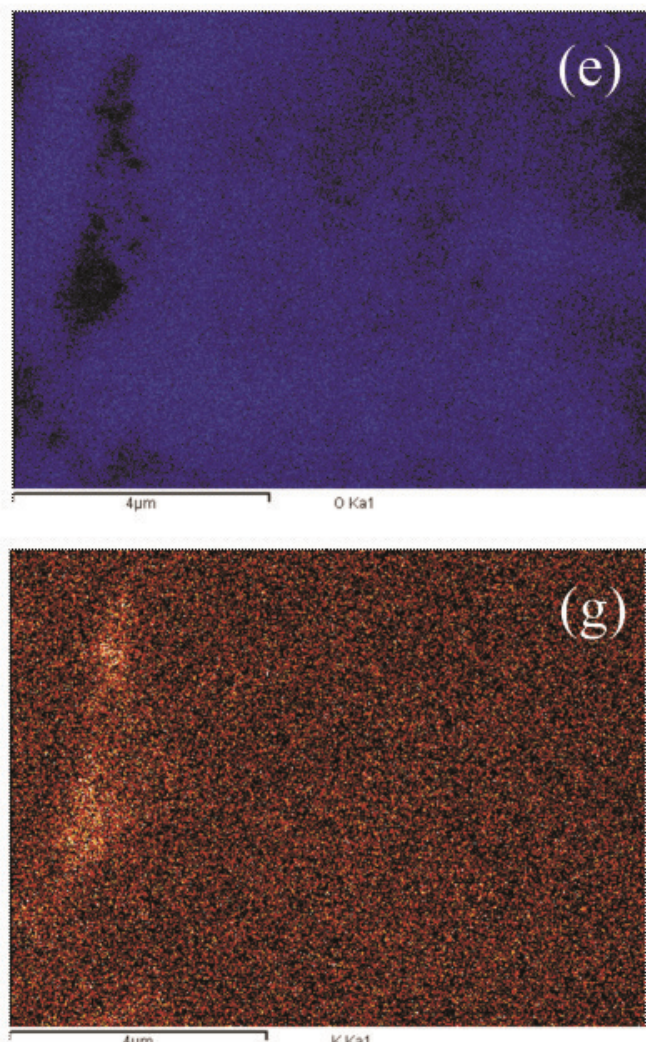

(g)

Figure 14. FE-SEM micrograph of the region of as-prepared sample with coated particles used for elemental mapping (a) and element maps for $\mathrm{Ni}(\mathrm{b}), \mathrm{Co}(\mathrm{c}), \mathrm{B}(\mathrm{d}), \mathrm{O}(\mathrm{e}), \mathrm{Si}(\mathrm{f}), \mathrm{K}(\mathrm{g})$ and $\mathrm{Ag}(\mathrm{h})$. Note: larger concentration of Ag, observed as brighter, is from the region of the sample relating to the silver paste substrate.
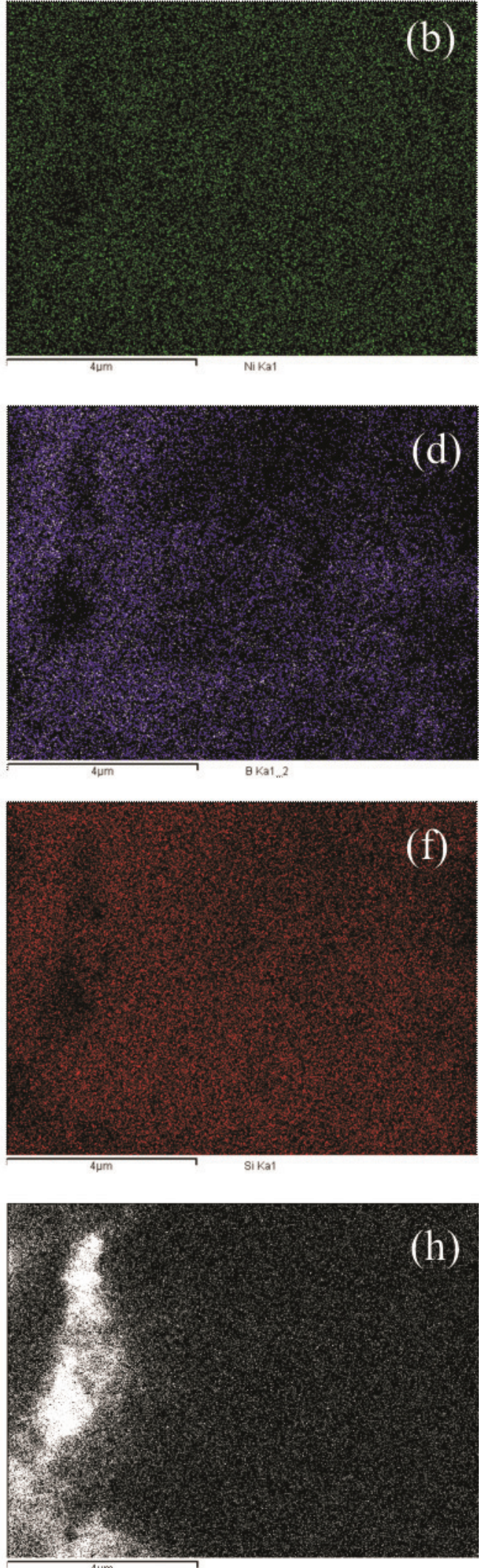

(h) 
was performed. FE-SEM micrograph of the region of the as-prepared sample with coated particles used for elemental mapping is shown in Figure 14 (a). Resulting element maps of constituent elements of the sample are shown in Figures 14 (b)-(h). A closer inspection of elemental maps for Ni and Co (Figures 14 (b) and (c)) reveals that these elements are evenly distributed along the samples with similar concentration. By comparing $\mathrm{Ni}$ and Co maps with that of B, Figure 14 (d), it can be seen that they are characterized with similar spatial distribution which may imply that $\mathrm{NiCoB}$ nanoparticles are present. Bigger concentration of boron observed from the corresponding map is explained by the excess of reducing media $\mathrm{KBH}_{4}$ used in synthesis procedure ${ }^{27}$. A similar spatial distribution but with enhanced concentration is also observed for $\mathrm{O}$ (Figure 14 (e)), indicating that a fraction of boron oxide has been also formed (throughout earlier proposed chemical reaction). Also, elemental mapping of the sample shows a uniform distribution $\mathrm{O}$ and $\mathrm{Si}$ on the surface of investigated particles (Figures 14 (e) and (f)), which may be due to thin $\mathrm{SiO}_{2}$ coating formation over the particles. A fraction of $\mathrm{K}$ is also evidenced along most parts of the sample with exception of evidently bigger concentration on the left hand side of the fragment of the sample under consideration (Figure $14(\mathrm{~g})$ ). This is the remnant from the sample preparation (as one shown in the region marked with A in Figure 4). Similar spatial distribution is evidenced for Ag (Figure 14 (h)). A larger concentration of silver is present on the sample holder, indicating that this is the response from the silver paste substrate.

EDS elemental mappings of annealed $\mathrm{NiCoB}$ samples with uncoated and coated particles showed similar spatial distributions of $\mathrm{Ni}, \mathrm{Co}$ and $\mathrm{B}$ in both cases. A bigger concentration of $\mathrm{Ni}$ and $\mathrm{Co}$ (with respect to $\mathrm{B}$ ) along with that of $\mathrm{O}$ (which has very similar spatial distribution with respect to $\mathrm{Ni}$ and $\mathrm{Co}$ ) indicates that some other phases (like $\mathrm{NiO}, \mathrm{CoO}$ ) may be formed in comparison to the as-prepared samples. The formation of these phases has been also confirmed by XRD, Figure 2 and Tables 1 and 2.

\section{CONCLUSION}

Amorphous alloy particles in $\mathrm{NiCoB}$ samples, uncoated and coated by $\mathrm{SiO}_{2}$, were prepared by using chemical reduction synthesis. The average diameter of nearly spherical uncoated nanoparticles was $(17 \pm 3) \mathrm{nm}$ and that of $\mathrm{SiO}_{2}$-coated particles was $(19 \pm 4) \mathrm{nm}$.

Structural measurements on the annealed $\mathrm{NiCoB}$ samples with uncoated and coated particles (annealed at $650{ }^{\circ} \mathrm{C}$ for 1 hour in argon atmosphere) revealed the formation of different crystalline phases. It indicated that $\mathrm{SiO}_{2}$ coating did not prevent oxidation of the samples and consequent formation of different crystalline phases during the heating process.

The fractions of all phases present in the annealed samples and sizes of coherently diffracting domains were obtained by Rietveld analysis. These sizes were in accordance with the sizes observed from FE-SEM observations (given in Table 3).

EDS quantitative measurements at different regions of as-prepared and annealed samples showed different morphologies and gave the average $\mathrm{Ni} / \mathrm{Co}$ ratio of $1.1 \pm 0.1$ in all $\mathrm{NiCoB}$ samples with uncoated and coated particles.

Acknowledgements. The research has been financially supported by the Unity Through Knowledge Fund within the program Cooper ability, Project UKF1B-01/07 to which we acknowledge. We greatly acknowledge Professor A. Tonejc, Professor S. Popović and Professor E. Babić for a careful reading of the manuscript and giving helpful comments.

\section{REFERENCES}

1. A. K. Gupta and M. Gupta, Biomaterials 26 (2005) 3995-4021.

2. P. Tartaj, M. P. Morales, S. Veintemillas-Verdaguer, T. González-Carreño, and C. J. Serna, J.Phys. D: Appl. Phys. 36 (2003) R182-197.

3. Q. A. Pankhurst, J. Connolly, S. K. Jones, and J. Dobson, J. Phys. D: Appl. Phys. 36 (2003) R167-181.

4. M. Zahn, J. Nanopart. Res. 3 (2001) 73-78.

5. I. Koh and L. Josephson Sensors 9 (2009) 8130-8145.

6. J. van Wonterghem, S. Mørup, C. J. W. Koch, S. W. Charles, and S. Wells, Nature 322 (1986) 622.

7. D. Buchkow, S. Nikolov, I. Dragieva, and M. Slavcheva, J. Magn. Magn. Mater. 62 (1986) 87.

8. S. Mørup, J. van Wonterghem, A. Meagher, and C. J. W. Koch, IEE Trans. Magn. 23 (1987) 2978.

9. I. Fernandez Barquin, G. D. Forster, N. S. Cohen, and Q. A. Pankhurst, J. Mater. Sci. Lett. 18 (1999) 425-426 and reference therein.

10. S. Wells, S. W. Charles, S. Mørup, S. Linderoth, J. van Wonterghem, J Larsen, and M. B. Madsen, J. Phys: Condens. Matter 1 (1989) 8199-8208.

11. W. Dudek, J.Gwiazda, E. Marianska, J. Oleniacz, and W. Zych, J. Magn. Magn. Mater. 86 (1990) 213.

12. P. Vavassori, F. Ronconi, and E. Puppin, J. Appl. Phys. 82 (1997) 6177.

13. J. Jiang, I. Dézsi, U. Gonser, and X. Lin, J. Non-Cryst. Solids 124 (1990) 139-144.

14. B. Molina Concha, R. D. Zysler, and H. Romero, Physica B 384 (2006) 274-276.

15. R. D. Zysler, H. Romero, C. A. Ramos, E. De Biasi, and D. Fiorani, J. Magn. Magn. Mater. 266 (2003) 233-242.

16. S. Mørup, S. A. Sethi, S. Linderoth, C. Bender Koch, and M. D. Bentzon, J. Mater. Sci. 27 (1992) 3010-3013.

17. A. Yedra, L. Fernández Barquin, R. Garcia Calderón, Q. A. Pankhurst, and J. C. Gómez Sal, J. Non-Cryst. Solids 287 (2001) 20-25.

18. S. Panday, B. S. S. Daniel, and P. Jeevanandam, J. Magn. Magn. Mater. 323 (2011) 2271-2280 and reference therein

19. C. Saiyasombat, N. Petchsang, I. M. Tang, and J. H. Hodak, Nanotechnol. 19 (2008) 085705-085712

20. M. Mustapić, D. Pajić, N. Novosel, E. Babić, K. Zadro, M. Cindrić, J. Horvat, Ž. Skoko, M. Bijelić, and A. Shcherbakov, 
Croat. Chem. Acta 83 (3) (2010) 275-282

21. W. A de Heer, P. Milani, and A. Chatelain, Phys. Rev. Lett. 65 (1990) 488

22. Q. Zhao, Y. Liu, Q. Shi, Z. Ma, and Z. Gao, J. All. Comp. 470 (2009) 443-447

23. M. Ivanda, A. M. Tonejc, I. Djerdj, M. Gotić, S. Musić, G Mariotto, and M. Montagna, Lecture Notes in Physics, in: Y. Watanabe, S. Heun, G. Salviati, and N. Yamamoto (Eds.), Nanoscale Spectroscopy and its Application to Semiconductor Re- search, Springer, New York, 2002, pp. 24-36.

24. I. Djerdj and A. M. Tonejc, J. Alloys Compd. 413 (2006) 159-174.

25. E. Mine, A. Yamada, Y. Kobayashi, M. Konno, and L. M. LizMarzón, J. Colloid Interface Sci. 264 (2003) 385-390.

26. J. Hájek, P. Mäki_Arvela, E. Toukoniitty, N. Kumar, T. Salmi, and D. Yu. Murzin, J. Sol-Gel Sci. Technol. 30 (2004) 187-195.

27. R. D. Zysler, C. A. Ramos, H. Romero, and A. Ortega, J. Mater. Sci. 36 (2001) 2291-2294. 